\title{
Kajian Fraktal k-Fibonacci Word Menggunakan Natural Drawing Rule
} (Fractal k-Fibonacci Word Using Natural Drawing Rule)

\author{
Ulfi Mega Prastiwi, Kosala Dwidja Purnomo, Firdaus Ubaidillah \\ Jurusan Matematika, Fakultas Matematika dan Ilmu Pengetahuan Alam, Universitas Jember (UNEJ) \\ Jln. Kalimantan 37, Jember 68121 \\ E-mail: kosala.fmipa@unej.ac.id
}

\begin{abstract}
Abstrak
Fraktal $k$-Fibonacci Word dapat dibentuk dari suatu barisan khusus dari bilangan biner $\{0,1\}$. Barisan ini didefinisikan secara rekursif sebagai, $f_{k, 0}=0, f_{k, 1}=0^{k-1} 1, f_{k, n}=f_{k, n-1}^{k} f_{k, n-2}$ untuk $n \geq 2$ dan $k \geq 1$. Pembangkitan fraktal $k$-Fibonacci word dapat dilakukan dengan cara memodifikasi barisan baru yaitu menggunakan barisan Dense Fibonacci Word untuk menghasilkan kurva fraktal dengan menggunakan tiga digit $\{0,1,2\}$, kemudian untuk membangkitkan kurva fraktalnya menggunakan aturan garis sederhana yang disebut natural drawing rule. Tujuan dari penelitian ini adalah bagaimana cara menerapkan natural drawing rule untuk membangkitkan kurva fraktal $k$-Fibonacci Word dan mengetahui perubahan bentuk kurva generalisasi $k$ genap dan $k$ ganjil. Karakteristik yang diperoleh untuk barisan Dense Fibonacci word generalisasi $k$ ganjil dan $k$ genap berbeda untuk generalisasi $k$ ganjil mempunyai kesamaan kurva $F_{k-2, n}$ sedangkan untuk generalisasi $k$ genap mempunyai kesamaan kurva yaitu $F_{k-4, n}$.
\end{abstract}

Kata Kunci: fraktal $k$-Fibonacci Word, barisan Dense Fibonacci Word, natural drawing rule

\section{Abstract}

Fractal $k$-Fibonacci Word can be formed from a special sequence of binary numbers $\{0,1\}$. This sequence is defined recursively as, $f_{k, 0}=0, f_{k, 1}=0^{k-1} 1, f_{k, n}=f_{k, n-1}^{k} f_{k, n-2}$ for $n \geq 2$ and $k \geq 1$. The fractal generation $k$ Fibonacci word can be done by modifying the new sequence ie using Dense Fibonacci Word sequence to generate fractal curves by using three digits $\{0,1,2$,$\} then to generate the fractal curves can be generated by natural drawing rule. The$ purpose of this research is how to apply natural drawing rule to generate fractal k-Fibonacci Word curve and to know the change of curve form generalization $k$ even and $k$ odd. The characteristics obtained for the Dense Fibonacci word generalization sequence $k$ odd and $k$ even different for the generalization of $k$ odd have the same curve $F_{k-2, n}$ where as for generalization even $k$ has the same curve ie $F_{k-4, n}$.

Keywords: $k$-Fibonacci word fractal, Dense Fibonacci word, natural drawing rule.

\section{PENDAHULUAN}

Ilmu matematika memberikan pengetahuan yang luas dalam kehidupan era modern seperti saat ini. Matematika lebih berkembang pesat saat mulai ditemukannya teknologi komputer. Melalui komputer manusia lebih mudah dalam mempelajari ilmu pengetahuan dalam berbagai bidang, salah satunya adalah perhitungan matematika. Geometri fraktal merupakan salah satu cabang dari ilmu matematika yang berkembang pesat dengan adanya komputer.

Geometri fraktal adalah ilmu matematika yang digunakan untuk mempelajari sifat-sifat dan prilaku fraktal yang tidak beraturan dan terpecah-pecah, serta mempelajari aspek-aspek rumit di alam sebagai suatu basis matematika [1]. Fraktal berasal dari bahasa latin "fractus" yang mempunyai arti patah atau bentuknya tidak beraturan. Fraktal memiliki sifat self-similarity, yaitu setiap bagian kecil dalam sebuah fraktal dapat dipandang sebagai replikasi skala kecil dari bentuk keseluruhan. Objek fraktal dibagi menjadi dua jenis yaitu himpunan fraktal dan fraktal alam. Beberapa contoh dari himpunan fraktal yaitu himpunan Cantor, segitiga Sierpinski, Koch snowflake, Mandelbrot set dan Julia set. Sedangkan contoh dari fraktal alam yaitu awan, gunung, jaringan sungai dan garis pantai [2].

Dumaine [3] mengatakan bahwa fraktal Fibonacci Word adalah salah satu jenis fraktal yang dihasilkan dari barisan Fibonacci Word yang berisi angka 1 dan 0 yang mempunyai makna geometris yaitu menggambarkan segmen garis pada arah tertentu. Fibonacci Word kemudian berkembang salah satunya yaitu menjadi k-Fibonacci Word yang pertama kali diperkenalkan oleh Ramirez dan Rubiano [4]. Barisan dari k-Fibonacci Word ini dapat didefinisikan secara rekursif sebagai $F_{k, 0}=0$; $F_{k, 1}=1 ; F_{k, n+1} F_{k, n}+F_{k, n-1} \quad n \geq 1 n$ menunjukkan suku ke-n dan $k$ menunjukkan generalisasi dari $k$-Fibonacci Word.

Pembangkitan fraktal k-Fibonacci Word menggunakan aturan ganjil genap mengacu berdasarkan pada barisan Fibonacci Word, sedangkan untuk menggambar barisan dari $k$-Fibonacci Word dapat dilakukan dengan cara memodifikasi barisan baru sehingga menjadikan aturan menggambarnya lebih sederhana. Barisan Dense Fibonacci Word adalah salah satu modifikasi yang digunakan untuk 
menghasilkan kurva fraktal dengan menggunakan tiga digit $\{0,1,2\}$, kemudian untuk membangkitkan kurva fraktalnya menggunakan aturan garis sederhana yang disebut natural drawing rule. Natural drawing rule merupakan aturan konstruksi dengan menghubungkan suatu kurva menggunakan gambar garis, mengikuti gerak dari simbol barisan Dense Fibonacci Word [5].

Berdasarkan uraian di atas, penulis tertarik untuk mengkaji lebih lanjut mengenai pembangkitan kurva fraktal $k$-Fibonacci Word berdasarkan barisan Dense Fibonacci Word dengan menggunakan natural drawing rule dan memvisualisasikan perubahan genaralisasi $\mathrm{k}$ ganjil dan $\mathrm{k}$ genap menggunakan software Matlab.

\section{METODE PENELITIAN}

Langkah-langkah yang dilakukan untuk menyelesaikan permasalahan ini diantaranya meliputi penafsiran fraktal kFibonacci Word berdasarkan barisan Dense Fibonacci Word. Langkah awal untuk melakukan penelitian ini adalah dengan cara menafsirkan fraktal k-Fibonacci Word berdasarkan barisan Dense Fibonacci Word. Pada langkah ini akan ditentukan aturan produksi untuk membangun fraktal k-Fibonacci Word. Bentuk fraktal k-Fibonacci Word juga dapat diperoleh dari hasil aturan produksi dengan menggunakan aturan ganjil-genap. Berdasarkan aturan yang tersedia maka akan diperoleh beberapa aturan dari fraktal kFibonacci Word. Pada langkah selanjutnya akan dilakukan penafsiran fraktal k-Fibonacci Word menggunakan natural drawing rule secara grafis sesuai dengan hasil dari generasi dan aturan produksi yang telah diberikan. Penafsiran fraktal k-Fibonacci Word menggunakan natural drawing rule secara grafis ini akan digambarkan hingga beberapa generasi sebagai pembanding dengan hasil visualisasi pada program. Langkah selanjutnya yaitu pembuatan program kFibonacci Word menggunakan natural drawing rule. Algoritma program penerapan natural drawing rule dalam membangun fraktal k-Fibonacci word meliputi menggunakan aksioma dan aturan produksi yang telah ada untuk menafsifkan barisan k-Fibonacci Word dan barisan Dense Fibonacci Word, menggunakan aksioma dan aturan produksi untuk variasi kurva, mendefinisikan simbol untuk menggambar $\{0,1,2\}$ sesuai dengan aturan natural drawing rule dengan posisi titik awal adalah $\left(X_{0}, Y_{0}\right)=(0,0)$ menghadap utara dan mengiterasikan nilai generasi hingga iterasi ke-n berdasarkan aksioma dan aturan produksi yang diberikan. Hasil yang diperoleh dari pembuatan program adalah visualisasi fraktal k-Fibonacci Word yang digunakan untuk mengetahui perubahan fraktal k-Fibonacci Word untuk $\mathrm{k}$ ganjil dan $\mathrm{k}$ genap secara visual. Analisis secara matematis juga digunakan untuk mengetahui perubahan $\mathrm{k}$ Fibonacci Word untuk $\mathrm{k}$ ganjil dan $\mathrm{k}$ genap untuk mengetahui bentuk kurva k-Fibonacci Word. Berdasarkan definisi barisan k-Fibonacci Word akan dikaji bagaimana identifikasi perubahan fraktal k-Fibonacci Word untuk generalisasi $\mathrm{k}$ ganjil dan $\mathrm{k}$ genap.

\section{HASIL DAN PEMBAHASAN}

Dalam tulisan ini barisan k-Fibonacci Word dinotasikan dengan $f_{n}$ sedangkan barisan Dense Fibonacci Word dinotasikan dengan $f_{n}^{\prime}$. Kurva fraktal k-Fibonacci Word dapat dibangkitkan berdasarkan barisan Dense Fibonacci Word dengan memulai penafsiran $n \geq 3$ karena bentuk kurva akan lebih terlihat pada $f_{3}^{\prime}$ hingga $f_{n}^{\prime}$ untuk memperolah bentuk kurva yang memiliki kemiripan dengan kurva lainnya. Penafsiran grafis barisan Dense Fibonacci Word dibangkitkan menggunakan natural drawing rule dengan menggunakan tiga digit $[0,1,2]$. Aturan menggambar natural drawing rule yaitu jika " 0 " maka menggambar suatu segmen garis, jika "1" maka menggambar segmen garis dan berbelok ke kanan, jika "2" maka menggambar segmen garis dan berbelok ke kiri, asumsikan sudut yang digunakan adalah $\frac{\pi}{2}$ dan posisi titik awal menghadap ke utara.

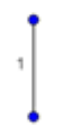

(a)

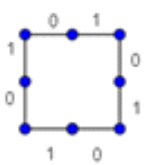

(d)

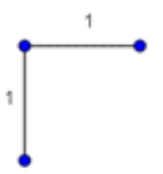

(b)

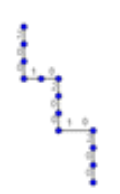

(e)

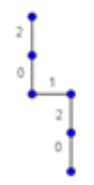

(c)

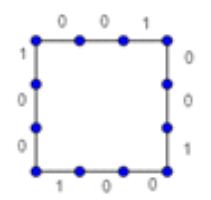

(f)
Gambar 1. Kurva k-Fibonacci Word (a) $F_{1,3}$, (b) $F_{2,3}$, (c) $F_{3,3},(\mathrm{~d}) F_{4,3},(\mathrm{e}) F_{5,3}$ dan (f) $F_{6,3}$.

Hasil yang diperoleh pada penafsiran grafis pada Gambar 1. di atas menunjukkan bahwa dengan barisan Dense Fibonacci Word yang mengandung beberapa digit angka yang hampir sama tetapi didalamnya menghasilkan jumlah segmen garis yang berbeda, meskipun terlihat mempunyai bentuk pola yang sama.

Visualisasi fraktal $k$-Fibonacci Word untuk $F_{3,13}$ hingga $F_{3,18}$ dapat dilihat pada Gambar 2.

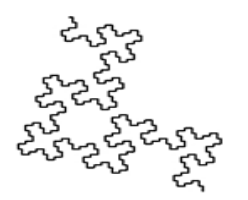

(a)

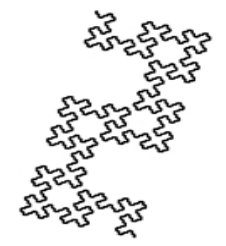

(c)

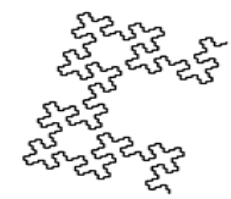

(b)

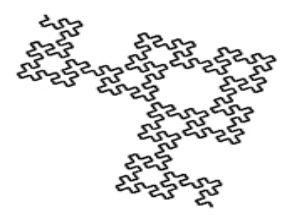

(d) 


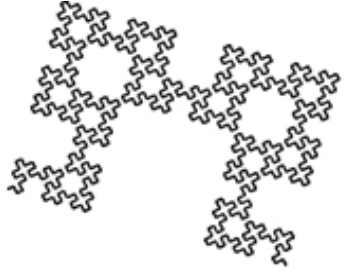

(e) (f)

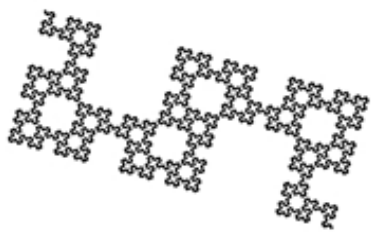

Gambar 2. Visualisasi Fraktal k-Fibonacci Word untuk
(a) $F_{3,13}$,
(b) $F_{3,14}$,
(c) $F_{3,15}$,
(d) $F_{3,16}$, (e)
$F_{3,17}$ dan
(f) $F_{3,18}$

Hasil visualisasi fraktal k-Fibonacci Word secara keseluruhan untuk nilai $k$ tetap dan nilai $n$ yang bervariasi ternyata menghasilkan bentuk kurva yang mempunyai pola yang hampir serupa dengan kurva yang sejajar terhadap sumbu $x$. Bentuk kurva fraktal k-Fibonacci Word yang dihasilkan mempunyai kesamaan dengan bentuk kurva fraktal Fibonacci Word, sifat kurva fraktalnya yaitu $F_{n}$ memiliki kemiripan dengan $F_{n-3}$, sedangkan pada kurva $k$-Fibonacci Word yaitu $F_{k, n}$ memiliki kemiripan dengan $F_{k, n-3}$. Karakteristik barisan Dense Fibonacci Word meliputi, pada barisan Dense Fibonacci Word dan ditemukan dua digit 1 dan 2 sebanyak dua kali (11) dan (22) sedangkan untuk 0 tidak ditemukan adanya dua digit 0 secara berturut-turut, selanjutnya yaitu pada barisan Dense Fibonacci Word $k \geq 3$ adalah kebalikan dari $f_{1}^{\prime}$ dan $f_{2}^{\prime}$ pada $k \geq 3$ tidak ditemukan digit 1 dan 2 sebanyak dua kali, melainkan ditemukan digit 0 secara berturut-turut dan terdapat sedikit perbedaan pada barisan Dense Fibonacci Word untuk generalisasi genap dan hal ini berpengaruh terhadap kurva fraktalnya itu sendiri. Untuk $f_{4}^{\prime}$ dan $f_{8}^{\prime}$ dalam barisannya mengandung perulangan 0 berjumlah genap, sedangkan untuk $f_{2}^{\prime}, \quad f_{6}^{\prime}$ dan $f_{10}^{\prime}$ mengandung perulangan 0 berjumlah ganjil.

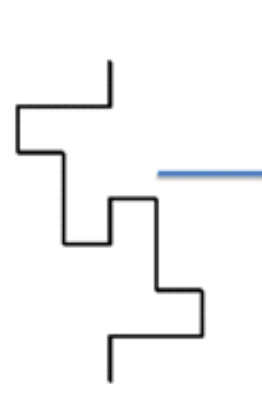

(a)

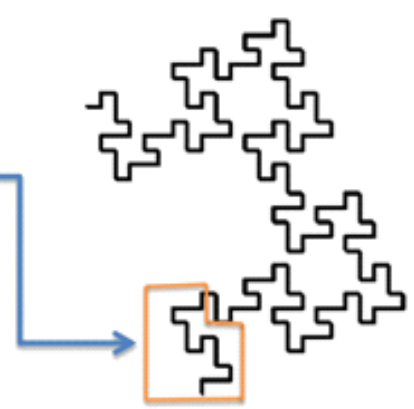

(b)
Gambar 3. Kurva k-Fibonacci Word (a) $F_{1,8}$ dan (b) $F_{1,13}$

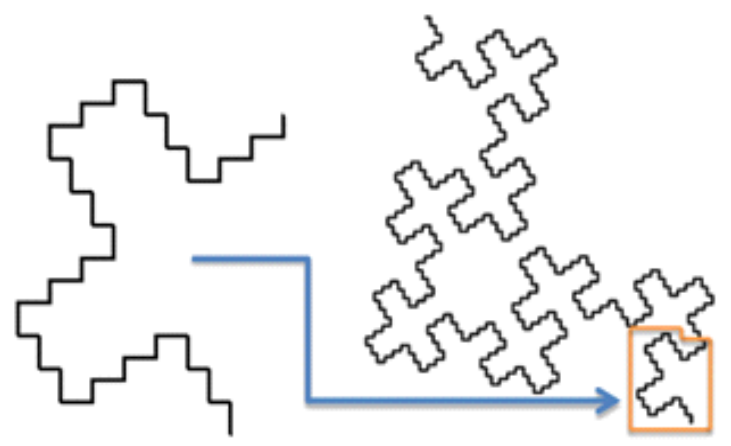

(a)

(b)

Gambar 4. Kurva k-Fibonacci Word (a) $F_{5,8}$ dan(b) $F_{5,13}$

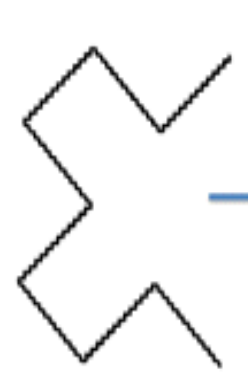

(a)

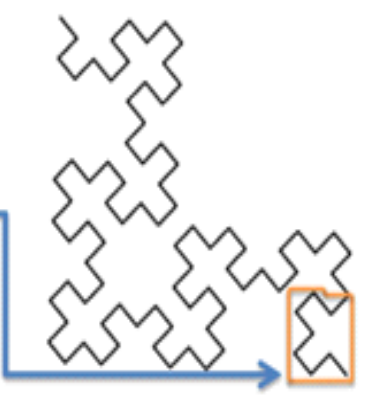

(b)
Gambar 5. Kurva k-Fibonacci Word (a) $F_{25,8}$ dan (b) $F_{25,13}$.

Hasil visualisasi pada Gambar 3, Gambar 4, dan Gambar 5 di atas menunjukkan bahwa gambar (a) merupakan potongan bagian kecil dari gambar (b) semakin besar $n$ yang diberikan maka kurva akan bertambah segmen garisnya, meskipun pada gambar (a) terdapat perbedaan sedikit pola pada tiap $k$ ganjilnya tetapi bentuk keseluruhan kurva pada gambar (b) memiliki keserupaan pada setiap $k$ generalisasi ganjil, semakin bertambahnya $k$ dan $n$ maka bentuk geriginya semakin tidak nampak hal ini disebabkan oleh sangat banyaknya segmen garis yang terbentuk.

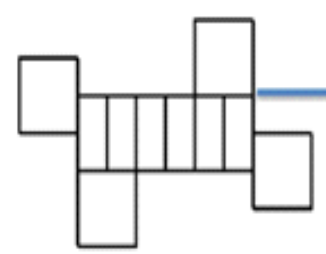

(a)

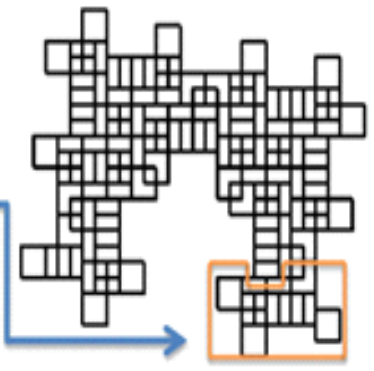

(b)
Gambar 6. Kurva k-Fibonacci Word (a) $F_{4,8}$ dan (b) $F_{4,13}$ 


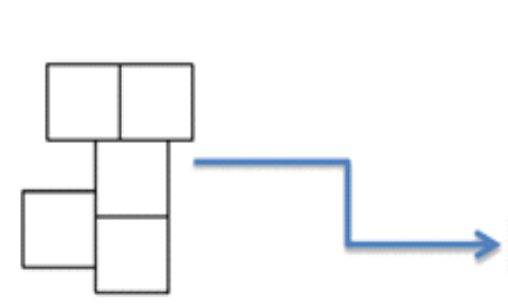

(a)

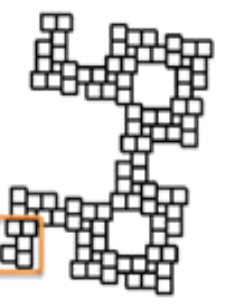

(b)

Gambar 7. Kurva k-Fibonacci Word (a) $F_{6,7}$ dan (b) $F_{6,13}$

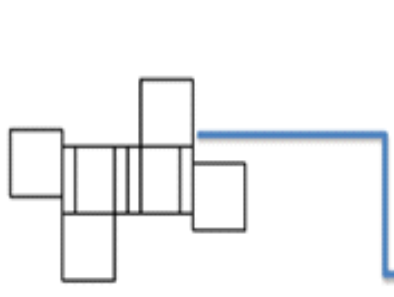

(a)

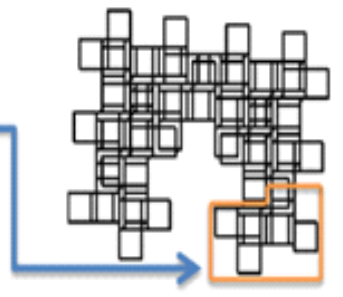

(b)
Gambar 8. Kurva k-Fibonacci Word (a) $F_{8,7}$ dan (b) $F_{8,13}$

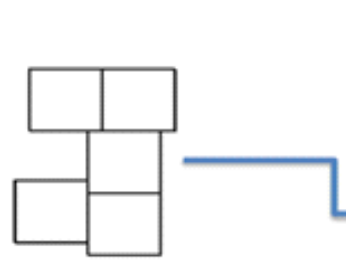

(a)

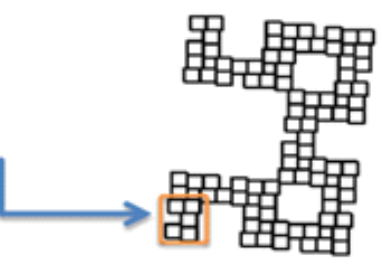

(b)
Gambar 9. Kurva k-Fibonacci Word (a) $F_{10,7}$ dan (b) $F_{10,13}$

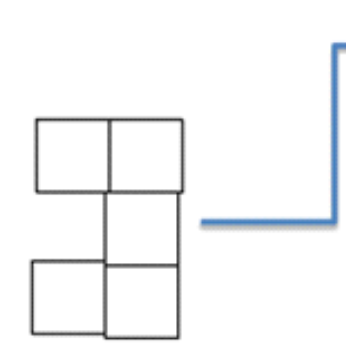

(a)

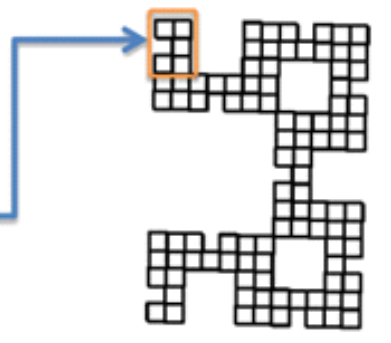

(b)
Gambar 10. Kurva k-Fibonacci Word (a) $F_{34,7}$ dan (b) $F_{34,13}$

Hasil visualisasi pada Gambar 6 hingga Gambar 10 di atas menunjukkan bahwa gambar (a) merupakan potongan bagian kecil dari gambar (b), meskipun pada gambar (a) terdapat perubahan pola dan pergeseran sedikit segmen garisnya tetapi mempunyai bentuk keseluruhan yang hampir serupa untuk $F_{k-4, n}$ dan semakin besar $k$ dan $n$ maka akan menghasilkan bentuk kurva yang konvergen pada bentuk persegi. Berdasarkan langkah-langkah yang telah dilakukan yaitu penafsiran k-Fibonacci Word berdasarkan barisan Dense Fibonacci Word dan dibangkitkan dengan Natural Drawing Rule di atas untuk $k$ ganjil dan $k$ genap diperoleh bahwa kurva $k$-Fibonacci Word memenuhi karakteristik sebagai fraktal yaitu memiliki sifat self-similarity, self-affinity, self-inverse dan self-squaring.

\section{KESIMPULAN}

Berdasarkan hasil dan pembahasan, diperoleh kesimpulan bahwa Fraktal k-Fibonacci Word dapat dibangkitkan menggunakan natural drawing rule berdasarkan barisan Dense Fibonacci Word dengan cara mengkonversi bilangan biner ke desimal $\{0,1,2\}$ untuk setiap pasangan angka dari barisan k-Fibonacci Word menjadi barisan Dense Fibonacci Word, dengan menggunakan metode natural drawing rule. Karakteristik fraktal $k$-Fibonacci Word generalisasi $k$ ganjil dan genap meliputi pada generalisasi $k$ ganjil bentuk kurva fraktalnya hampir sama antara $k$ ganjil yang satu dengan yang lain yaitu $F_{k-2, n}$. Pada generalisasi $k$ genap bentuk kurva fraktalnya mempunyai kesamaan yaitu $F_{k-4, n}$, kurva $k$ Fibonacci Word merupakan family curve dari fraktal Fibonacci word karena karakteristiknya memiliki kemiripan.

\section{DAFTAR PUSTAKA}

[1] Peitgen, H.O. dan Soupe, D. 1988. The Science of Fractal Images. New York: Springer-Verlag.

[2] Mandelbrot, B. B. 1977. The Fractal Geometry of Nature. New York: W. H. Freeman and Company.

[3] Dumaine, A. M. 2009. The Fibonacci Word Fractal. https://hal.archivesouvertes.fr/file/index/docid/367972 filename/The Fibonacci word fractal.pdf.[11 November 2017].

[4] Ramirez, Jose L dan G.N.Rubiano. 2013. Properties and Generalizations of the Fibonacci Word Fractal. London: IOP Publishing.

[5] Wright, D. J. Dynamical Systems and Fractals Lecture.

http://www.math.okstate/fractals/mathdept/dynamics/1 ecnotes/lecnotes.html.[11November2017]. 